\title{
The Application of Ideal Efficiency Analysis Mode on Contactless Excitation Energy Transmission System
}

\author{
Jinfeng Liu, Xudong Wang and Meicun Yan \\ School of Electrical \& Electronic Engineering, Harbin University of Science \& \\ Technology, Harbin, China \\ ljf78118@163.com
}

\begin{abstract}
As a brand of new power transfer system, contactless energy transmission system can be used to improve the security, dependability and flexibility of the power system. Contactless energy transmission technology is suitable for some special fields, so it has already been received the great concern of foreign academia and international engineering technological circle. Energy coupling realized by contactless magnetic tank transformer as new approach of rotator excitation in synchronous machine could replace brushes and slip rings of traditional excitation. This system reduces size, weight and cost of excitation system to great extent. First, a suitable model needs to be founded because contactless energy transfer system is different from the switching power supply. We found the mutual inductance model and then gived a detailed discussion on the loosely coupled magnetic tank transformer. In accordance with the condition of the most power transmission we use the harmonic technique to realize compensation and propose series-series topology. In order to obtain the stable system the harmonic frequency of primary zero phase angle and critical load resistance could be determined based on this circuit. Second, the ideal efficiency analysis mode was proposed to simplify efficiency analysis process. In this process, the ideal efficiency determined by load resistance was introduced into the expression of input and output power and made sure of the last efficiency of contactless excitation energy transmission system. Last, when the air gap and input signal frequency have been maintained, we study the impact on the contactless energy transmission efficiency when the input signal waveform and average power changes. We selected the square wave, sine wave and triangular wave as the input signals. It will provide certain reference for the performance analysis of magnetic tank transformer.
\end{abstract}

Keywords: magnetic tank transformer; contactless excitation; harmonic compensation; ideal efficiency analysis

\section{Introduction}

Generally, sliding contact power supply has been used widely to supply power for Excitation systems for synchronous machines and equipments of electric vehicle and electric train in urban transportation. However, this kind of method has some defects such as sliding abrasion, touching spark and carbon deposit, for example [1,2]. Therefore, new contactless power transfer technology has been invented to improve these detects which based on new technology about induction energy transfer theory. The character by using induction technology is the relative sites of subsystem are stable, and it can realize closed coupled and high transfer efficiency, for example [3, 4]. The core device of this system to achieve contactless electrical energy transfer is rotary separable magnetic tank transformer, which 
utilizes the benefit about transfer efficiency won't be influenced by rotate speed when primary or secondary winding of magnetic tank transformer keep rotating state.

\section{Consist of Contactless Excitation Power Transmission System}

Contactless excitation power transmission system using the theory of electromagnetic induction to achieve synchronous motor excitation energy transfer and the diagram of the energy transmission is shown in Figure 1.

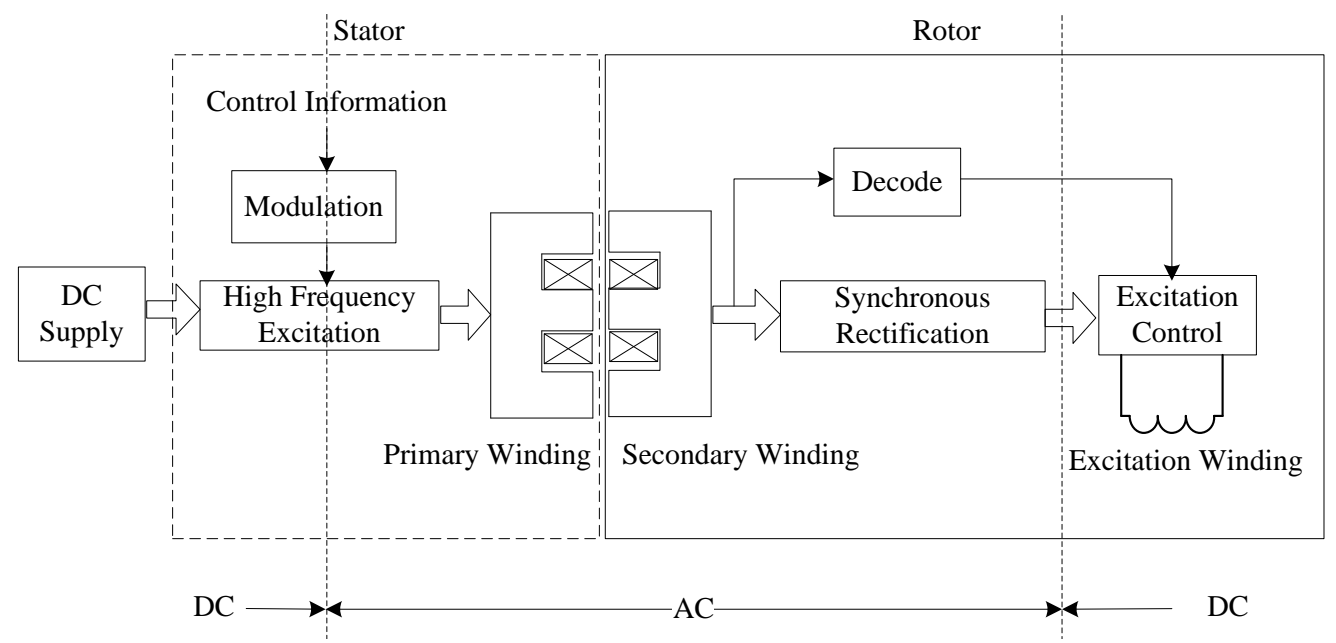

Figure 1. Power transmission system

Energy transmission diagram is composed of two parts when magnetic tank transformer is the cut-off point. On the left side of the dotted box is the synchronous motor stator, which provided DC power by the on-board battery, as the same time it provides high-frequency alternating current transformer to primary winding through the high frequency excitation inverter. Primary winding induces energy to secondary winding by electromagnetic coupled and then provide energy to the excitation winding of synchronous motor by synchronous rectification. Secondary winding can determine the increasing magnetic mode or weakening magnetic mode of the synchronous motor through decoding.

\section{Analysis of Primary and Secondary Equivalent Circuit Impedance}

The influence of secondary system to primary system is reflected by the $Z_{r}$, for example [5]. In other words, $Z_{\mathrm{r}}$ represents the influence of secondary circuit load on primary circuit current in transformer and becomes the equivalent impedance in primary circuit. Due to the load resistance $R_{o}$ is greater than the coil internal resistance, so we can ignore the coil internal resistance in order to simplify analysis. Reflection impedance not only reflects the power transmission performance of the system directly but also reflects the complex of the impedance, for example [6]. Figure 2 shows primary and secondary of the transformer equivalent circuit which is expressed by reflection impedance. $\mathrm{V}_{\mathrm{s}}$ is primary excitation voltage, $L_{1}$ and $L_{2}$ are primary inductance and secondary inductance respectively, $M$ is the mutual inductance of the contactless transformer, $R_{o}$ is the load resistance. In order to improve system performance and the ability to power transmission, the resonance compensation technology is used in primary winding and secondary winding respectively. 
Analysis on reflection impedance as follows:

$$
Z_{r}=\frac{j \omega M I_{2}}{\square}=R_{r}+j X_{r}
$$

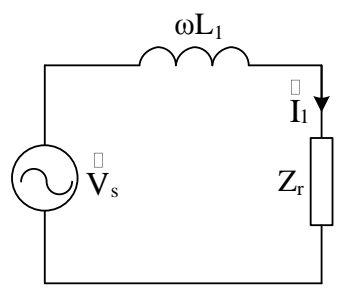

(a) Primary Winding

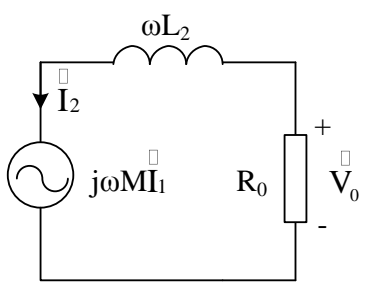

(b) Secondary Winding

Figure 2. Primary and secondary equivalent circuit

$R_{r}$ is reflection resistance and $X_{r}$ is reflection reactance. According to the theory of circuit, we can respectively get the plural equation of primary and secondary circuits and then obtain primary and secondary current expression. Put current expression into (1) and get reflection resistance and reflection reactance of secondary system that reflected to primary system when compensation circuit isn't used in secondary system.

$$
\begin{gathered}
R_{r}=\frac{\omega^{2} M^{2} R_{0}}{\omega^{2} L_{2}^{2}+R_{0}^{2}} \\
X_{r}=-\frac{\omega^{3} M^{2} L_{2}}{\omega^{2} L_{2}^{2}+R_{0}^{2}}
\end{gathered}
$$

Secondary system of the transformer reflected to the primary system is the capacitive impedance without compensation circuit in secondary system.

\section{Capacitance Compensation}

Primary winding of the contactless transformer always connects with the switch of converter, and then primary voltage will be loaded on the switch directly, so primary winding current all flow through the switch and lead to the high rating value of voltage and current, for example [7]. Through the resonance of the compensation capacitor $C_{1}$ and primary winding inductance $\mathrm{L}_{1}$, it will compensate the voltage on primary winding, that is to say the voltage on the compensation capacitor $\mathrm{C}_{1}$ will offset the voltage on primary winding $\mathrm{L}_{1}$ partly or completely and reduce the voltage stress of switching tube at the same time. According to the conditions of primary series resonance we can get series compensation capacitor $C_{1}$ is:

$$
C_{1}=\frac{1}{\omega^{2} L_{1}}
$$

The contactless magnetic tank transformer secondary windings are connected to the load directly, the output voltage and current of the converter will change with the change of load, so secondary system must be compensated, for example [8]. At the resonance of the compensation capacitor $\mathrm{C}_{2}$ and secondary inductance $\mathrm{L}_{2}$, we can take secondary winding as a resistance which the output voltage doesn't related to the load. So secondary induction voltage can be seen as constant voltage source. According to the resonance conditions of secondary series resonance we can get series resonance compensation capacitance $\mathrm{C}_{2}$ is: 


$$
C_{2}=\frac{1}{\omega^{2} L_{2}}
$$

When the series resonance compensation is used to secondary winding the reflection impedance is:

$$
Z_{r}=\frac{\omega^{4} C_{2}^{2} M^{2} R_{0}-j \omega^{3} C_{2} M^{2}\left(1-\omega^{2} C_{2} L_{2}\right)}{\left(1-\omega^{2} C_{2} L_{2}\right)^{2}+\omega^{2} C_{2}^{2} R_{0}^{2}}
$$

When secondary compensation circuit is in resonance state:

$$
\omega=\frac{1}{\sqrt{L_{2} C_{2}}}
$$

The reflection impedance is simplified :

$$
Z_{r}=\frac{\omega^{2} M^{2}}{R_{0}}
$$

The reflection impedance of secondary winding is resistance when the series resonance compensation is used to secondary winding. The quality factor of primary winding and secondary winding can be got according to the structure of the series - series resonance circuit:

$$
\begin{aligned}
& Q_{1}=\frac{\omega L_{1}}{R_{1}}=\frac{\sqrt{L_{1} / C_{1}}}{R_{1}} \\
& Q_{2}=\frac{\omega L_{2}}{R_{2}}=\frac{\sqrt{L_{2} / C_{2}}}{R_{2}}
\end{aligned}
$$

Magnetic tank transformer and winding size are designed as follows: outside diameter $10 \mathrm{~mm} \times$ inside diameter $4 \mathrm{~mm} \times$ height $8 \mathrm{~mm}$ on core, outside diameter $9 \mathrm{~mm} \times$ inside diameter $4 \mathrm{~mm} \times$ height $8 \mathrm{~mm}$ on winding, primary number of turns and secondary number of turns are 24. It will get the parameters as follows: $\mathrm{L}_{1}=276.2 \mu \mathrm{H}, \mathrm{L}_{2}=263.3 \mu \mathrm{H}, \mathrm{M}=200 \mu \mathrm{H}, \mathrm{R}_{1}=\mathrm{R}_{2}=$ $0.26 \Omega$, Series compensation capacitor $\mathrm{C}_{1}=\mathrm{C}_{2}=7.5 \mu \mathrm{F}$.

\section{Analysis of System Efficiency}

The system stability of the contactless excitation power transmission is the foundation of the system can be widely used. If there will be maximum power transfer for electrical energy transmission system, the resonance frequency must be equal to the frequency of operation, for example [9] and [10]. But it may also create problems for the frequency control system, then lead to the unstability of the system and make the system transmission capacity decline. If there are more than one zero phase angle point within the scope of spectrum, it is difficult to determine the ideal control points. There may be multiple resonance point and make the system frequency out of control when load changes. In order to ensure stability and power transmission capacity of system, only one zero phase angle frequency under various operating conditions must be guaranteed. Resonance frequency is generally believed that is the frequency of the impedance angle is zero. According to the literature analysis, in order to maintain stability and maximum power transfer primary zero phase angle resonance point should be secondary resonance frequency point. So the optimal frequency operation point of system could be designed on the basis of transformer equivalent circuit parameter:

$$
f=\frac{1}{2 \pi \sqrt{L_{2} C_{2}}}=4 \mathrm{kHz}
$$


The boundary conditions of stable operation for series-series compensation topology is :

$$
R_{o c}>\frac{\sqrt{2} k \omega L_{2}}{\sqrt{1+\sqrt{1-k^{2}}}}
$$

According to the boundary conditions can make sure critical load resistance value $\mathrm{R}_{0}$ of stable operation system when transformer coupled coefficient $\mathrm{k}$ was determined.

According to the formula of mutual inductance and calculation (4) and (5) of resonant compensation capacitance we can get:

$$
M=k \sqrt{L_{1} L_{2}}=\frac{k}{\omega} \sqrt{L_{1} / C_{2}}=\frac{k}{\omega} \sqrt{L_{2} / C_{1}}
$$

We can calculate the equivalent input resistance $Z_{\mathrm{s}}$ of the circuit from Figure 3.

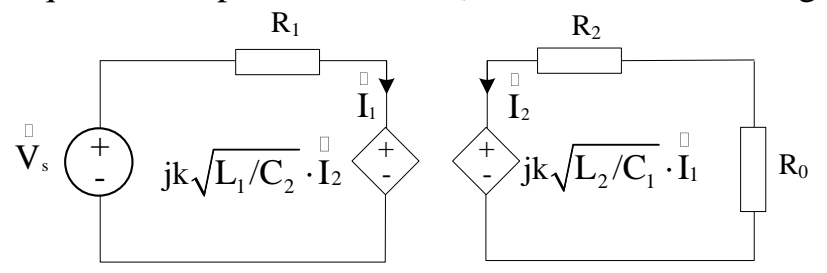

Figure 3. Simplified equivalent circuit

The conclusion would be obtained according to the KVL:

$$
\begin{aligned}
& V_{s}=R_{1} I_{1}+j k \sqrt{L_{1} / C_{2}} I_{2} \\
& j k \sqrt{L_{2} / C_{1}} I_{1}+\left(R_{0}+R_{2}\right) I_{2}=0
\end{aligned}
$$

Equivalent input resistance is:

$$
Z_{s}=\frac{V_{s}}{I_{1}}=R_{1}+\frac{k^{2} \sqrt{L_{1} / C_{2}} \cdot \sqrt{L_{2} / C_{1}}}{R_{0}+R_{2}}=R_{1}\left[1+k^{2} Q_{1} Q_{2}\left(1-\eta_{x}\right)\right]
$$

$\eta_{\mathrm{x}}$ is the deal efficiency of the contactless transformer with the capacitance compensation.

$$
\eta_{x}=\frac{R_{0}}{R_{0}+R_{2}}
$$

Electromagnetic coupled coefficient is:

$$
k=\frac{1}{\left(1+\frac{\sqrt[3]{4} d^{2}}{r_{1} r_{2}}\right)^{3 / 2}}
$$

In this formula $\mathrm{d}$ is the coil spacing between primary and secondary winding, $\mathrm{r}_{1}$ is effective radius of primary winding, $r_{2}$ is effective radius of secondary winding. And $r_{1}$ or $r_{2}$ is the average of inside radius and outside radius of windings. Output power calculation can be got as $\mathrm{P}_{0}=\left|\mathrm{V}_{0}\right|^{2} / 2 \mathrm{R}_{0}$ according to transformer provide maximum power to the load. The expression of output power based on ideal efficiency is:

$$
P_{0}=\frac{V_{s}^{2}}{2 R_{1}} \cdot \frac{k^{2} Q_{1} Q_{2}\left(1-\eta_{x}\right) \eta_{x}}{\left[1+k^{2} Q_{1} Q_{2}\left(1-\eta_{x}\right)\right]^{2}}
$$

On the basis of the input power calculation, the expression of input power based on ideal efficiency is:

$$
P_{s}=\mathfrak{R}\left\{V_{s} I_{s}^{*} / 2\right\}=\frac{V_{s}^{2}}{2 R_{1}} \cdot \frac{1}{1+k^{2} Q_{1} Q_{2}\left(1-\eta_{x}\right)}
$$

So the efficiency expression of power transmission system for contactless transformer is: 


$$
\eta=\frac{k^{2} Q_{1} Q_{2}\left(1-\eta_{x}\right) \eta_{x}}{1+k^{2} Q_{1} Q_{2}\left(1-\eta_{x}\right)}
$$

\section{Simulation and Experiment Analysis}

With the condition of stable operation, the simulation and experimental analysis was done and compared with the result in order to validate the correctness of the ideal efficiency analysis model on transformer system.

\subsection{Simulation and Experiment on Zero Phase Angle Resonance Point of Primary System}

Under the condition of zero phase Angle resonance point in primary system, The frequency of switch transistor is $4 \mathrm{kHz}$, the DC input voltage of the high-frequency converter is $40 \mathrm{~V}$ and load is $10 \Omega, 51 \Omega$ and $1 \mathrm{k} \Omega$ respectively. The output efficiency were tested under different load. The comparison of the simulation and experimental research are shown as Figure 4.

From simulation and experiment research we can deduce conclusions. First, although there would be certain error between theoretical calculated value and measured value of efficiency in the system under different load, it's all controlled below 5\% and changing trend is accordance. So it's clear that ideal efficiency analysis model has certain correctness. Secondly, under the influence of $51 \Omega$ load, the output power is above $90 \mathrm{~W}$ when the air gap is $400-700 \mu \mathrm{m}$. The air gap of iron core in contactless magnetic tank transformer was set $500 \mu \mathrm{m}$ based on this result. The coupled coefficient can be determined according to the structural parameters of transformer, and then the system critical load resistance can be determined $\mathrm{R}_{\mathrm{oc}}>40 \Omega$ from expression(12). This means system meet the stable operation condition under $51 \Omega$ load. Finally, efficiency contrast of simulation and experiment as shown as Fig.8 could validate that the efficiency is above $95 \%$ under $51 \Omega$ load and $500 \mu \mathrm{m}$ air gap. So higher efficiency could be got when the critical load resistance is obtained according to the stable operation condition under reasonable air gap. And the error between simulation and experimental results is minimum in high efficiency area.

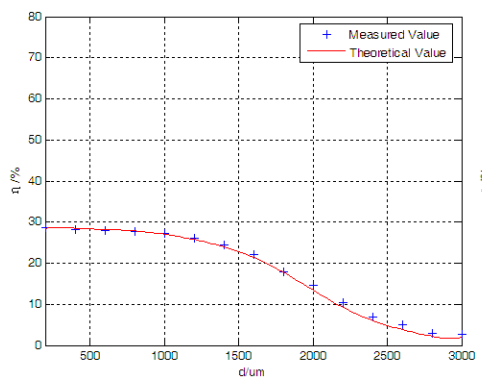

(a) $\mathrm{R}_{0}=10 \Omega$

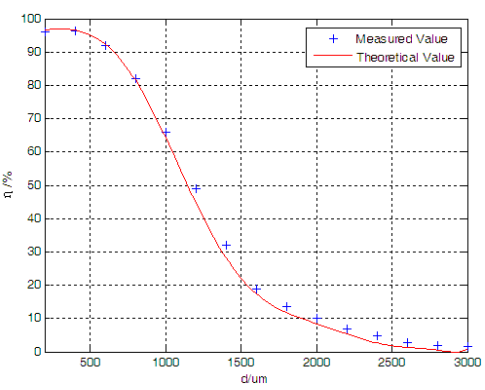

(b) $\mathrm{R}_{0}=51 \Omega$

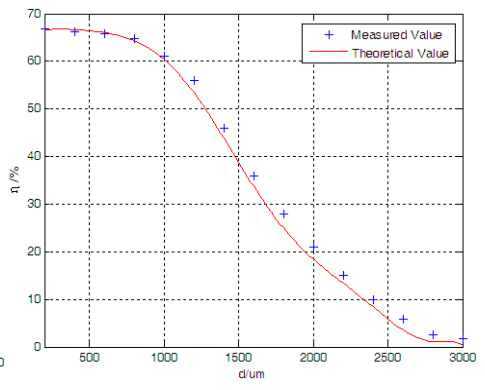

(c) $\mathrm{R}_{0}=1 \mathrm{k} \Omega$

Figure 4. Efficiency comparison of the Experiment and simulation about the output power and efficiency under different load

\subsection{Simulation and Experiment under Secondary Critical Load Resistance}

When secondary system load is critical load resistance and the air gap is $500 \mu \mathrm{m}$ the simulation and experiment of the output-power and efficiency under different working frequency are shown as Figure 5(a) and (b). 


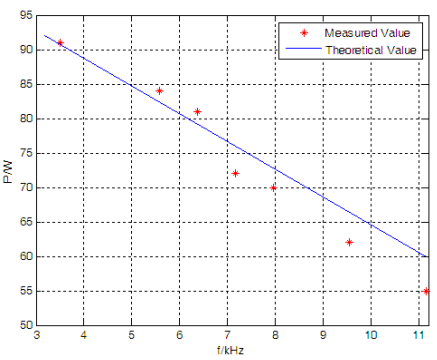

(a) $\mathrm{P}_{\mathrm{o}}$

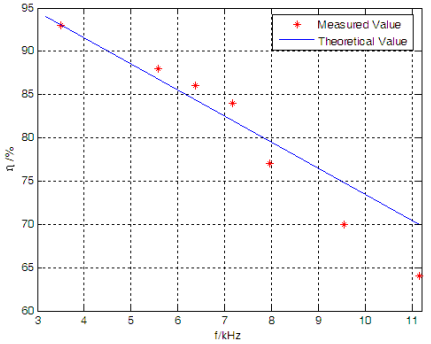

(b) $\eta$

Figure 5. The comparison of the Experiment and simulation about the output power and efficiency under different frequency

From the contrast we can seen that system output power and efficiency are decreasing when the frequency is increased. When the system works in secondary resonance frequency points $4 \mathrm{KHz}$, output power and efficiency of the simulation and experimental results are basically identical. With the increase of operating frequency, the error between the simulation and experimental results also will increase. So once the working frequency of the system deviates from secondary resonance frequency points, not only can not run efficiently, but also the ideal efficiency analysis model is also poor.

\section{Study on the Relationship between Waveform and Power of Signal and Energy Transmission Efficiency}

The change of input signal waveform and power will also have some influence on the contactless energy transmission efficiency in the process of research. The research results of this section will provide some help and reference on contactless energy transmission technology field.

\subsection{Choice of input signal waveform}

The square wave, sine wave and triangular wave are the most typical signal waveform in all kinds of AC signal waveform. The experiment selected these three kinds of periodic signal as input signal of contactless energy transmission circuit and the signal frequency are unified as $4 \mathrm{kHz}$.

\subsection{Analysis on relationship between waveform and power of signal and energy transmission efficiency}

8.2.1. Energy transmission efficiency analysis on same waveform and different power of signal:Derivation 1-Peak voltage of input signal will change with input power. $\Delta \mathrm{V}_{\mathrm{s}} / \Delta \mathrm{t}$ can change with $\mathrm{Vs}$ because signal frequency is invariant. Suppose $\Delta \mathrm{V}_{\mathrm{s}} / \Delta \mathrm{t}$ changes to $\mathrm{K}$ times and then input voltage Vs also changes to $\mathrm{K}$ times. $\Delta \mathrm{I}_{\mathrm{s}} / \Delta \mathrm{t}$ changes to $\mathrm{K}$ times on the basis of Kirchhoff's voltage law, so input current $\mathrm{I}_{\mathrm{s}}$ changes to $\mathrm{K}$ times. Consequently, input power $\mathrm{P}_{\mathrm{s}}$ changes to $\mathrm{K}^{2}$ times. Derivation 2-According to Gauss's Law and Biot Savart Law, we can derive:

$$
\frac{\Delta \phi}{\Delta t}=\frac{\mu_{0} R^{2} S}{2 r^{3}} \frac{\Delta I_{s}}{\Delta t}
$$

$\Delta \Phi / \Delta \mathrm{t}$ is magnetic flux changing rate, $\Delta \mathrm{I}_{\mathrm{S}} / \Delta \mathrm{t}$ is current changing rate of primary winding, $\mu_{0}$ is permeability of vacuum, $R$ is radius of circle coil, $r$ is the distance from any point on axis 
to any point on coil. So $\Delta \Phi / \Delta \mathrm{t}$ changes to $\mathrm{K}$ times when $\Delta \mathrm{I}_{\mathrm{s}} / \Delta \mathrm{t}$ changes to $\mathrm{K}$ times according to equation (21).Expression of self induced electromotive force:

$$
E=\frac{n \Delta \phi}{\Delta t}=\frac{L \Delta I_{0}}{\Delta t}
$$

$\mathrm{n}$ is coil turns, $\mathrm{L}$ is self induction coefficient, $\Delta \mathrm{I}_{\mathrm{o}} / \Delta \mathrm{t}$ is current changing rate of secondary winding. Ohm's Law varying form is:

$$
\frac{\Delta V}{\Delta t}=Z \frac{\Delta I}{\Delta t}
$$

$\mathrm{Z}$ is circuit impedance. Combined equation (22) and (23):

$$
\frac{\Delta \phi}{\Delta t}=\frac{L}{n Z} \frac{\Delta V_{0}}{\Delta t}
$$

According to equation (24) $\Delta \mathrm{V}_{\mathrm{o}} / \Delta \mathrm{t}$ changes to $\mathrm{K}$ times and induced output voltage $\mathrm{V}_{\mathrm{o}}$ changes to $\mathrm{K}$ times when $\Delta \Phi / \Delta \mathrm{t}$ changes to $\mathrm{K}$ times. According to equation (23) induced output current $\mathrm{I}_{\circ}$ changes to $\mathrm{K}$ times when $\Delta \mathrm{I}_{\mathrm{o}} / \Delta \mathrm{t}$ changes to $\mathrm{K}$ times. So output power $\mathrm{P}_{\mathrm{o}}$ changes to $\mathrm{K}^{2}$ times. On the basis of derivation 1 and derivation 2 conclusion is as follows: signal energy transmission efficiency is invariable when the power of the same waveform signal is changed.

8.2.2. Energy transmission efficiency analysis on same input power and different waveform of signal: Derivation $1-$ When $\Delta \mathrm{V}_{\mathrm{s}} / \Delta \mathrm{t}$ is higher we can derive that $\Delta \mathrm{I}_{\mathrm{s}} / \Delta \mathrm{t}$ is higher by equation (23), $\Delta \Phi / \Delta \mathrm{t}$ is higher by equation (21), $\Delta \mathrm{V}_{\mathrm{d}} / \Delta \mathrm{t}$ is higher by equation (24), then $\mathrm{V}_{\mathrm{o}}$ is higher. $\Delta \mathrm{I}_{\mathrm{o}} / \Delta \mathrm{t}$ is higher by equation (23) and then Io is higher. So input power $\mathrm{P}_{\mathrm{o}}$ will still higher.

Derivation 2-When $\Delta \mathrm{V}_{\mathrm{s}} / \Delta \mathrm{t}$ is lower we can derive that $\Delta \mathrm{I}_{\mathrm{s}} / \Delta \mathrm{t}$ is lower by equation (23), $\Delta \Phi / \Delta \mathrm{t}$ is lower by equation (21), $\Delta \mathrm{V}_{\mathrm{o}} / \Delta \mathrm{t}$ is lower by equation (24), then $\mathrm{V}_{\mathrm{o}}$ is lower. $\Delta \mathrm{I}_{\mathrm{o}} / \Delta \mathrm{t}$ is lower by equation (23) and then $I_{o}$ is lower. So output power $P_{o}$ will still lower.

On the basis of derivation 1 and derivation 2 conclusion is as follows: signal power which is derived by mutual inductance coupler secondary winding is higher when input signal is square signal, so energy transmission efficiency of square signal is highest. Then energy transmission efficiency of triangular signal is lower and energy transmission efficiency of sine signal is medium.

Considering the energy level provided by the equipment is small we must minimize the energy loss in experimental circuit and unnecessary devices and ensure the results is accurate and reliable. So the most simple circuit is designed in order to reduce the length and components of circuit. It's shown as Figure 6

$\mathrm{R}_{\mathrm{p}}$ and $\mathrm{R}_{\mathrm{s}}$ is experiment resistance, $\mathrm{C}_{1}$ and $\mathrm{C}_{2}$ is primary and secondary compensation capacitance respectively. Signal generator will provide $5 \mathrm{~V}$ power signal for experiment equipment. Dual measuring method is used by oscilloscope.

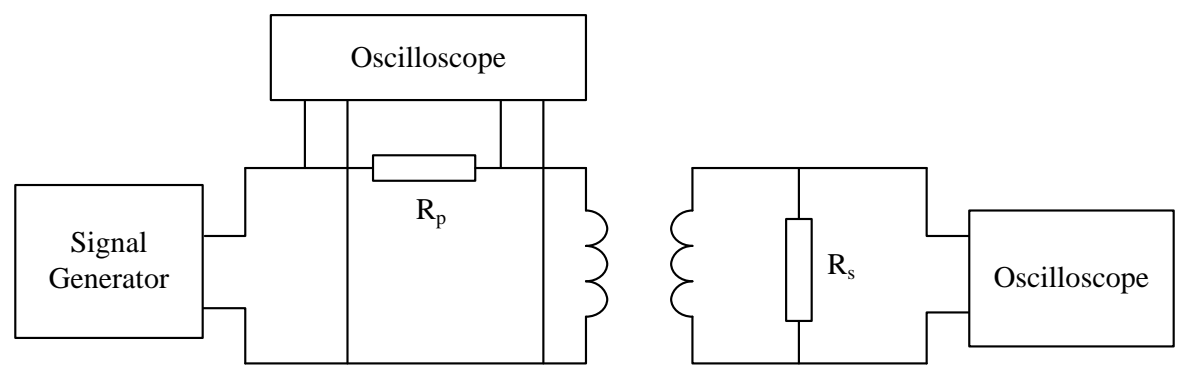

Figure 6. Experiment circuit 


\subsection{Analysis of experiment data}

8.3.1. Validation of energy transmission efficiency on same waveform and different input power:Square wave, sine wave and triangular wave of different power was inputed into experiment equipment respectively and obtained data. Then the power and transmission efficiency can be calculated. Experiment and calculation results are shown as Table 1-Table 3 .

Conclusion based on experiment data and calculation is the change rate of input and output average power is identical to the input signal with same waveform. The experiment results and conclusion obtained by theoretical analysis are completely consistent.

Table 1. Experiment data of square wave input signal under different power

\begin{tabular}{|c|c|c|c|c|c|}
\hline $\begin{array}{l}\text { Voltage } \\
\text { of } \\
\text { primary }(\mathrm{V})\end{array}$ & $\begin{array}{l}\text { Voltage } \mathrm{V}_{1} \\
\text { of primary } \\
\text { resistance } \\
\mathrm{R}_{\mathrm{p}}(100 \Omega)(\mathrm{V})\end{array}$ & $\begin{array}{l}\text { Voltage } \mathrm{V}_{2} \\
\text { of secondary } \\
\text { resistance } \\
\mathrm{R}_{\mathrm{s}}(100 \Omega)(\mathrm{V})\end{array}$ & $\begin{array}{l}\text { Primary } \\
\text { power } \\
\mathrm{P}_{\mathrm{s}}(\mathrm{mW})\end{array}$ & $\begin{array}{l}\text { Secondary } \\
\text { power } \\
\mathrm{P}_{\mathrm{o}}(\mathrm{mW})\end{array}$ & $\begin{array}{l}\text { Energy } \\
\text { transmission } \\
\text { efficiency } \\
\eta(\%)\end{array}$ \\
\hline 2 & 0.524 & 0.341 & 10.48 & 1.163 & 11.096 \\
\hline 4 & 1.12 & 0.781 & 44.8 & 6.099 & 13.615 \\
\hline 6 & 1.435 & 1.223 & 86.1 & 14.957 & 17.372 \\
\hline 8 & 2.074 & 1.896 & 165.92 & 35.948 & 21.666 \\
\hline 10 & 2.312 & 2.247 & 231.2 & 50.490 & 21.838 \\
\hline 12 & 3.156 & 2.974 & 378.72 & 88.447 & 23.354 \\
\hline
\end{tabular}

Table 2. Experiment data of sine wave input signal under different power

\begin{tabular}{|c|c|c|c|c|c|}
\hline $\begin{array}{l}\text { Voltage } \mathrm{V}_{\mathrm{s}} \\
\text { of } \\
\text { primary }(\mathrm{V})\end{array}$ & $\begin{array}{l}\text { Voltage } \mathrm{V}_{1} \\
\text { of primary } \\
\text { resistance } \\
\mathrm{R}_{\mathrm{p}}(100 \Omega)(\mathrm{V})\end{array}$ & $\begin{array}{l}\text { Voltage } \mathrm{V}_{2} \\
\text { of secondary } \\
\text { resistance } \\
\mathrm{R}_{\mathrm{s}}(100 \Omega)(\mathrm{V})\end{array}$ & $\begin{array}{l}\text { Primary } \\
\text { power } \\
\mathrm{P}_{\mathrm{s}}(\mathrm{mW})\end{array}$ & $\begin{array}{l}\text { Secondary } \\
\text { power } \\
\mathrm{P}_{\mathrm{o}}(\mathrm{mW})\end{array}$ & $\begin{array}{l}\text { Energy } \\
\text { transmission } \\
\text { efficiency } \\
\eta(\%)\end{array}$ \\
\hline 2 & 0.412 & 0.253 & 8.24 & 0.640 & 7.768 \\
\hline 4 & 0.967 & 0.582 & 38.68 & 3.387 & 8.757 \\
\hline 6 & 1.223 & 0.996 & 73.38 & 9.920 & 13.519 \\
\hline 8 & 1.759 & 1.57 & 140.72 & 24.649 & 17.516 \\
\hline 10 & 2.107 & 2.081 & 210.7 & 43.306 & 20.553 \\
\hline 12 & 2.861 & 2.754 & 343.32 & 75.845 & 22.092 \\
\hline
\end{tabular}

Table 3. Experiment data of triangular wave input signal under different power

\begin{tabular}{|c|c|c|l|l|l|}
\hline $\begin{array}{l}\text { Voltage } \\
\text { of } \\
\text { primary }(\mathrm{V})\end{array}$ & $\begin{array}{l}\text { Voltage } \mathrm{V}_{1} \\
\text { of primary } \\
\text { resistance } \\
\mathrm{R}_{\mathrm{p}}(100 \Omega)(\mathrm{V})\end{array}$ & $\begin{array}{l}\text { Voltage } \mathrm{V}_{2} \\
\text { of secondary } \\
\text { resistance } \\
\mathrm{R}_{\mathrm{s}}(100 \Omega)(\mathrm{V})\end{array}$ & $\begin{array}{l}\text { Primary } \\
\text { power } \\
\mathrm{P}_{\mathrm{s}}(\mathrm{mW})\end{array}$ & $\begin{array}{l}\text { Secondary } \\
\text { power } \\
\mathrm{P}_{\mathrm{o}}(\mathrm{mW})\end{array}$ & $\begin{array}{l}\text { Energy } \\
\text { transmission } \\
\text { efficiency } \\
\eta(\%)\end{array}$ \\
\hline 2 & 0.301 & 0.196 & 6.02 & 0.384 & 6.381 \\
\hline 4 & 0.827 & 0.49 & 33.08 & 2.401 & 7.258 \\
\hline 6 & 1.097 & 0.781 & 65.82 & 6.1 & 9.267 \\
\hline 8 & 1.642 & 1.43 & 131.36 & 20.449 & 15.567 \\
\hline 10 & 2.065 & 1.982 & 206.5 & 39.283 & 19.023 \\
\hline 12 & 2.757 & 2.654 & 330.84 & 70.437 & 21.29 \\
\hline
\end{tabular}


8.3.2. Validation of energy transmission efficiency on same input power and different waveform:Table 1 to Table 3 also shows that contactless energy transmission efficiency is different when input signal waveform is different. We can choose same input power to compare transmission efficiency because energy transmission efficiency of three waveform signal will not change with input power. Experiment results shows contact energy transmission efficiency rate of three waveform signal is: square wave/sine wave/triangular wave $=23.35 / 22.09 / 21.29$. The experiment results and conclusion obtained by theoretical analysis are completely consistent.

\section{Conclusions}

This paper studied contactless magnetic tank transformer as the key component of energy transmission system. And this system can work as the harmonic status through capacitance compensation and it will obtain stable system. Ideal efficiency analysis mode was proposed in this paper, and this mode would simplify efficiency analysis process.Simulation and experiment indicate that analysis error of output power and efficiency based on ideal efficiency analysis mode is less than 0.05 , and the trend of simulation under different load or frequency is coordinated with the trend of experiment when all stable running conditions are fulfilled.

\section{Acknowledgements}

This work is supported by National Natural Science Foundation (51177031). My deepest gratitude goes first and foremost to Professor Wang Xudong, my supervisor, for his constant encouragement and guidance. He has walked me through all the stages of the writing of this thesis. Without his consistent and illuminating instruction, this thesis could not have reached its present form. Second, I would like to express my heartfelt gratitude to Professor Yang Fang, who led me into the world of Power electronic. Last my thanks would go to my beloved family for their loving considerations and great confidence in me all through these years. I also owe my sincere gratitude to my friends who gave me their help and time in helping me work out my problems during the difficult course of the thesis.

\section{References}

[1] A, Ikuo, "Design theory of Wireless Power System Based on Magnetically Coupled Resonators", IEEE Int'l Conference on wireless Information Technology and System, Honolulu, United States, (2010) May 20-22.

[2] M. Franco, C. Alessandra and D, Marco, "Harmonic Balance Design of Wireless Resonant-type power transfer Links", IEEE International Microwave Workshop Series on Innovative Wireless Power Transmission, Kyoto, Japan, (2012) June12-14.

[3] L. Ying and J. Vikram, "Design of retrodirective antenna arrays for short-range wireless power transmission", IEEE Transactions on Antennas and Propagation, vol. 4, no. 60, (2002).

[4] G. Kamil, A. T. Ryan and W. Chuck, "Loosely coupled wireless power transfer: Physics, circuits, standards", IEEE International Microwave Workshop Series on Innovative Wireless Power Transmission, Kyoto, Japan, (2012) May 8-10.

[5] Z. Wei, C. Qianhong and S. C. Wong, "Reluctance Circuit and Optimization of a Novel Contactless Transformer", Proceedings of the CSEE, vol. 10, no. 30, (2010).

[6] C. Chin-Jung, C. Tah-Hsiung and L. Chih-Lung, "A Study of Loosely Coils for wireless power transfer", IEEE Transactions on Circuits and System, vol. 8, no. 57, (2010).

[7] F. Kyriaki and F. W. Brian, "Wireless power transfer in loosely coupled links: Coil misalignment model", IEEE Transactions on Magnetics, vol. 5, no. 47, (2011).

[8] A. Ikuo and K. Takuya, "A Simple design of resonator-coupled wireless power transfer", IEEJ Transactions on Electronics, Information and System, vol. 2, no. 130, (2010).

[9] C. Liu, J. Zou and X. Fu, "Characteristic analysis of contactless transformer", Fifth International Symposium on Instrumentation Science and Technology, Shenyang, China, (2009) September 15-18.

[10] H. Nobumi, "Study on the principle of contactless electric power transfer via electromagnetic coupling", Electrical Engineering in Japan, vol. 2, no. 182, (2013). 